\title{
Analysis of electrical explosion of wire systems for the production of nanopowder
}

\author{
RASHMITA DAS*，BASANTA KUMAR DAS，ROHIT SHUKLA, \\ T PRABAHARAN and ANURAG SHYAM
}

Energetics and Electromagnetics Division, Bhabha Atomic Research Centre, Autonagar, Visakhapatnam 530012, India

e-mail: rashmita78@gmail.com

MS received 25 May 2011; revised 4 May 2012; accepted 26 July 2012

\begin{abstract}
Nanoscience and nanotechnology continue to grow as fields of scientific research and commercial development as many fundamental properties are size dependent on the nano scale. There are so many techniques for the production and characterization of various ultra fine powders. To gain a fundamental understanding of size dependant properties of matter in the nanometer size regimes and to develop nanoscale materials into useful devices to benefit society requires detailed study of the experimental methods, better methods of sample preparation of mono dispersed material in large quantities, and development of nanoparticles characterization methods. Exploding wire method is one such method for the production of metal and metal oxide nanoparticles capable of producing bulk amount of metal nanoparticles at low cost. With the intention of developing better exploding wire system for the production of nanoparticle and to understand the nanoparticle formation process, we have developed two systems in the way of optimization of the experimental set-up for final production of nanoparticles. The detail analysis of the systems and its effect on the nanoparticles has been described in the paper.
\end{abstract}

Keywords. Nanopowder; EEW; XRD.

\section{Introduction}

Presently the formation of nanostructures with controlled size and morphologies has been focus of intensive research. To make them useful in industry, lot of efforts are being given on the functionalization and production of particles of particular particle distribution and morphology (Grassian 2008). So research in the direction of the development of better experimental system is the demand of the present situation. Many alternative methods have been proposed to realize production of particles. Electrical explosion of wire method (EEW) is one of the vapour phase methods in which particles are produced by evaporating a thin metal wire by passing high current

*For correspondence 
through it (Kotov et al 1995; Mao et al 2009; Muraia et al 2002; Suematsu et al 2007). In this paper, the emphasise has been given to explain the process involved to produce nano phase material by EEW method experimentally.

\section{Theory}

For a wire of length ' $l$ ' and diameter ' $d$ ', power dissipated into the wire due to flow of current $I(t)$ is proportional to

$$
P(t)=\frac{\rho \cdot l}{s} \cdot I(t)^{2},
$$

$\rho$ is the resistivity of the material, ' $s$ ' is the cross section of the wire.

If $e$ is the internal energy per unit mass of the material, then at any point of time power dissipated into wire can be written as

$$
\begin{gathered}
P(t)=m \cdot d e / d t, \\
\frac{\rho \cdot l}{s} . I(t)^{2}=m \cdot d e / d t,
\end{gathered}
$$

where $m$ is the mass of the wire and resistivity is a function of deposited energy, so above equation can be rearranged to

$$
\begin{aligned}
\frac{l}{s \cdot m} \cdot I(t)^{2} d t & =\frac{1}{\rho(e)} d e, \\
\frac{I(t)^{2}}{\gamma \cdot s^{2}} . d t & =\frac{1}{\rho(e)} d e,
\end{aligned}
$$

$\gamma$ is the density of the material. Up to the point of vaporization, the above equation can be written as

$$
\frac{1}{s^{2}} \int_{0}^{t_{b}} I(t)^{2} d t=\gamma \int_{e_{0}}^{e_{v}} \frac{1}{\rho(e)} d e=a,
$$

where $a$ is called the action integral of the material and as the right hand side of the integral is solely dependent on material properties and hence considered constant for any material. This is derived by taking the heating as to be slow adiabatic. However for exploding wire experiments, $a$ needs to be multiplied by $a$ factor $\mathrm{k}_{1}$, where $1<\mathrm{k}_{1}<3$. Action of copper is $1.31 \times 10^{17}$ $\mathrm{A}^{2} \operatorname{sec~} \mathrm{m}^{-4}$ (Neuber 2005). For explosion of the wire, the action of the system should be nearly equal to required action of copper.

\section{Experimental techniques}

The electrical exploding wire experiment is performed by suddenly discharging an electrically stored energy source through a fine wire. The basic circuit is shown in figure 1. Two wire exploding circuits have been built, which have approximately the same circuit parameters $(\mathrm{C}=7.1 \mu \mathrm{f}$ and voltage $10 \mathrm{kV}$ ). The major difference is the inductance of the system and the method of mounting the wire. One exploder is a cage type open system (set-up I) where wires are mounted 


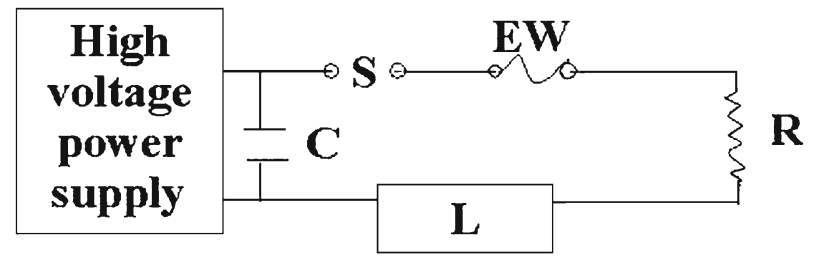

\section{S: Spark gap \\ EW:Exploding wire \\ R: Resistance of circuit \\ L: Inductance of the circuit \\ C: Capacitor}

Figure 1. Circuit diagram for exploding wire experiment.

between two parallel plates. The other exploder (set-up II) is a confined chamber. The experimental set-up was arranged so that it is possible to measure on a single wire simultaneously the voltage across the wire and the current flowing through the wire. The inductance of set-up I and set-up II is $146 \mathrm{nH}$ and $910 \mathrm{nH}$, respectively. The voltage was measured by voltage divider which is placed across the wire and the current monitor is placed in the periphery of the discharging cable connected between capacitor and wire terminating at circuit ground. Discharge current of experimental set-up I is shown in figure 2 and for set-up II is shown in figure 3 . Current curve form exploding wire system is always typical and always takes the attention of the researcher while designing experimental set-up. Burst phenomenon depends on the cross section of the wire. The powder was prepared by exploding the copper wire (purity $99.95 \%$ of copper) of $0.26 \mathrm{~mm}$ and $0.19 \mathrm{~mm}$ in experimental set-up I and set-up II, respectively.

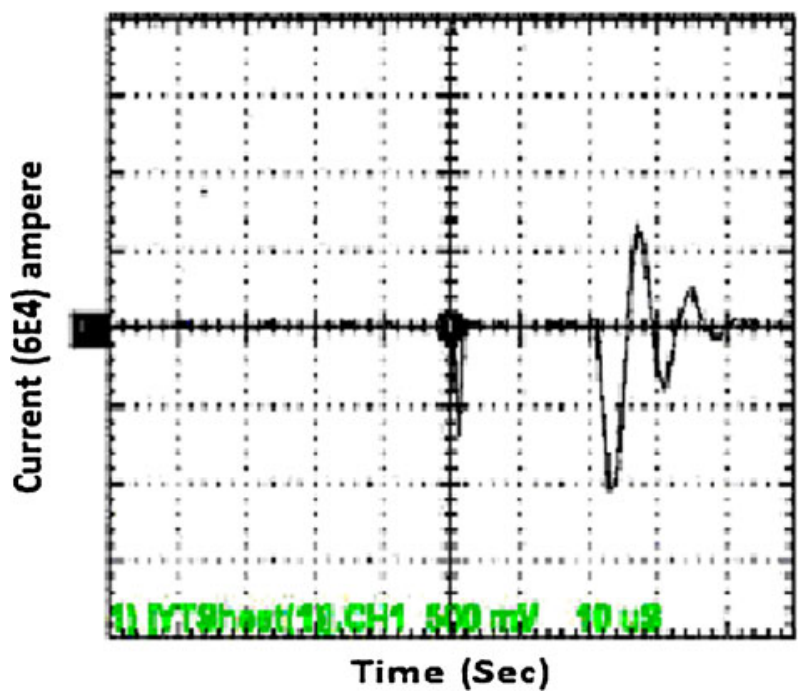

Figure 2. Discharge current of experimental set-up I. 


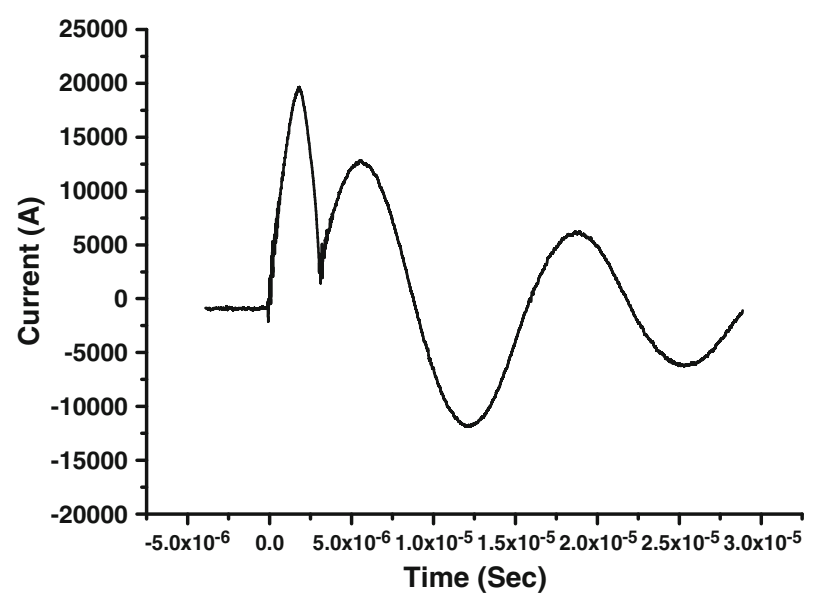

Figure 3. Discharge current of experimental set-up II.

\subsection{Explanation of current wave form in set-up I}

Current in the exploding wire system depends on the inductance of the system. In experimental set-up I, to reduce the inductance of the circuit, the connecting path between the capacitor output terminals and the end of the wire was done by using 6 parallel connecting paths by the use of copper rods of same length and diameter. The current monitor used is of 0.001 (V/A) monitor and connected to the oscilloscope through $20 \mathrm{~dB}$ attenuator. The factor of $6 \times 10^{4}$ in the graph indicates the actual current measured after taking care of parallel current path, attenuator, and current monitor ratio. Peak current measured was found to be $42 \mathrm{kA}$. The current wave form consists of three phases, explosion of the wire in the first peak, current dwell, and restriking. But for the nanoparticle formation energy deposited into the wire during explosion is of the interest, which controls the metal aerosol formation as well as nucleation rate. So the energy injected to the wire during the first current pulse is given by Kotov (2003).

$$
W=\left(a W_{0} S^{2} Z\right)^{0.5}
$$

$a$ is the measured action integral of material, $\mathrm{W}_{0}=\mathrm{CV}_{0}^{2} / 2$ is the stored energy, $\mathrm{V}_{0}$ is the capacitor charging voltage; $\mathrm{Z}=(\mathrm{L} / \mathrm{C})^{0.5}$ is the circuit characteristic impedance, $\mathrm{L}$ is the discharge circuit inductance, $\mathrm{C}$ is the capacitance, and $\mathrm{S}$ is the wire cross-sectional area. Action integral obtained from measured current curve is found to be $1.5 \times 10^{17} \mathrm{~A}^{2} \mathrm{sec} / \mathrm{m}^{4}$. Measured $\mathrm{Z}$ is $0.143 \mathrm{ohm}$, stored energy in the capacitor is calculated to be 355 joule and the cross section area of wire $0.26 \mathrm{~mm}$ diameter is given by $0.053 \times 10^{-6} \mathrm{~m}^{2}$. From these energy injected into wire, calculated from measured current curve, was found to be 145 Joule.

\subsection{Explanation of current wave form in set-up II}

Discharge current wave form for experimental set-up indicates the absence of dwell. This is the condition when explosion occurred, avalanching was not prevented; hence, the restrikes occurred immediately. For this set-up action integral obtained from measured current curve is found to be $2.2 \times 10^{17} \mathrm{~A}^{2} \mathrm{sec} / \mathrm{m}^{4}$. Measured $\mathrm{Z}$ is $0.358 \mathrm{ohm}$, stored energy in the capacitor is calculated to 


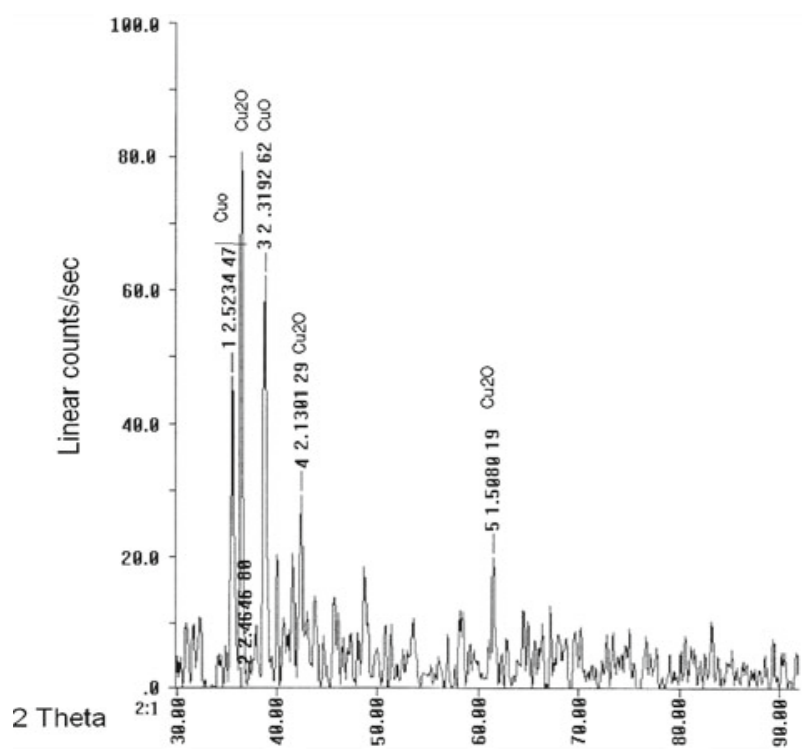

Figure 4. XRD Pattern of the sample for set-up I.

be 355 joule and the cross section area of wire $0.19 \mathrm{~mm}$ diameter is given by $0.0283 \times 10^{-6} \mathrm{~m}^{2}$. From these energy injected into wire calculated from measured current curve was found to be 149 Joule.

\subsection{Characterization}

Powder X-ray diffraction (XRD) measurement were performed by using $\mathrm{K}_{\alpha}$ line of copper $(\lambda=$ $1.5 \AA$ ). XRD pattern of the sample for experimental set-up I is shown in figure 4 . XRD pattern of the sample for experimental set-up II is shown in figure 5. Mean particle size of the powder

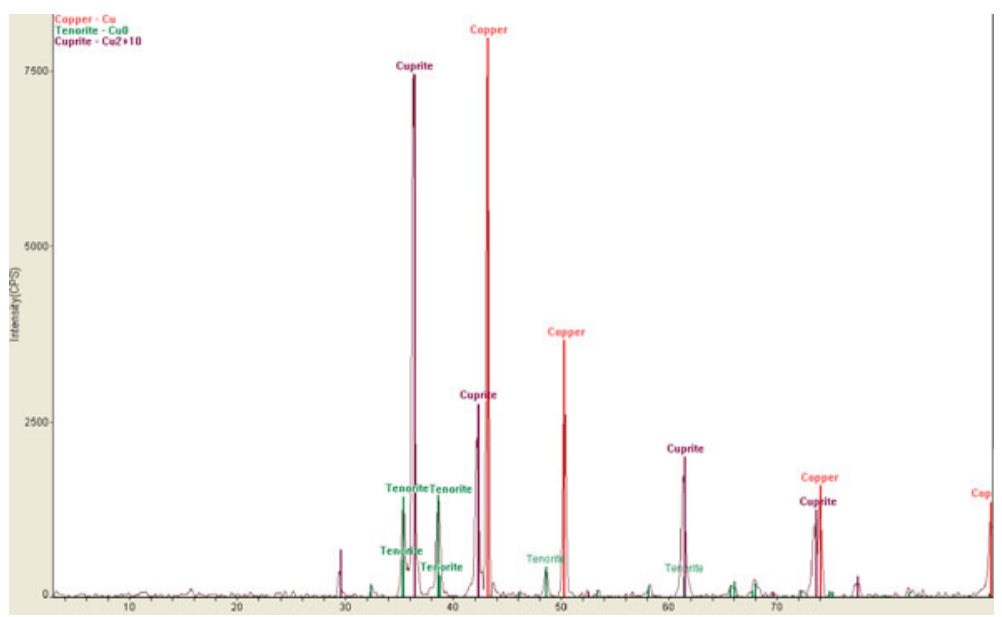

Figure 5. XRD Pattern of the sample for set-up II. 


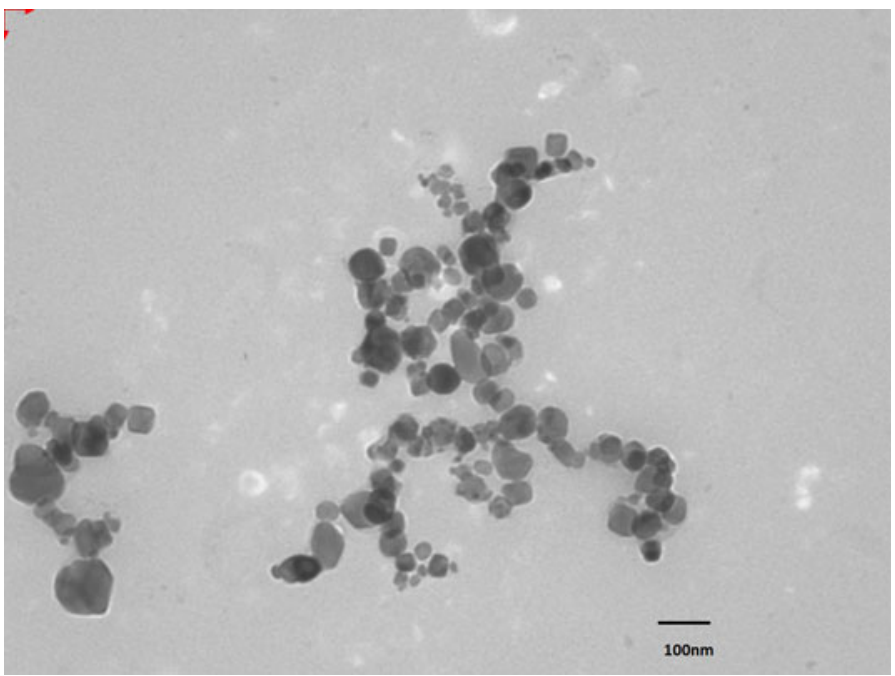

Figure 6. TEM image of the sample for set-up I.

was determined from multiple images obtained from transmission electron microscope (TEM). TEM image of the sample collected for the set-up I and set-up II are shown in figures 6 and 7. The average size of the particle for experimental set-up I was found out to be $45 \mathrm{~nm}$ and for experimental set-up II, it was found to be $51.82 \mathrm{~nm}$.

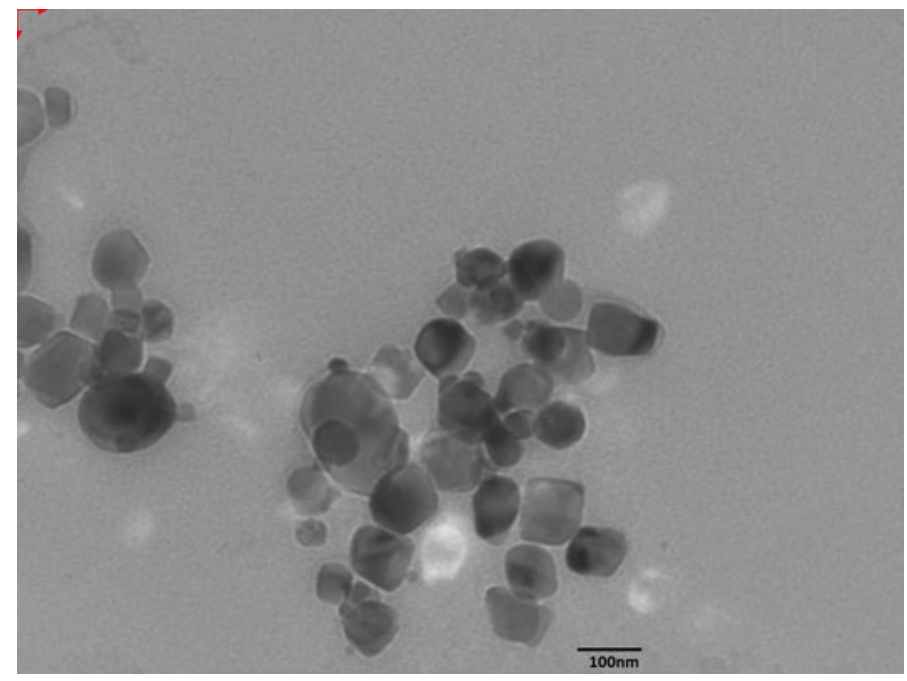

Figure 7. TEM image of the sample for set-up II. 


\section{Conclusion}

Vapourization energy required for the wire is around 207 joule for $1^{\text {st }}$ wire and 110.5 joule for second wire, but with the deposited energy into the wire being nearly same. For the first experimental set-up energy deposited is less than the vapourization energy required and for the second that is more than the required vapourization energy. The result of both the experimental set-up explains the process of formation of nano phase material clearly. In the electrical explosion wire method, the injected energy into the wire need not to be more than required vapourization energy to produce nano phase materials as explained in literature. The necessary and sufficient condition that has to be met is the burst condition. The nucleation of metal liquid droplet, expansion of metal vapour or both can lead to nano phase material. Our future study will have the detailed analysis of the ambient condition and the rate of reaction of liquid metal and vapour to get the desired size and shape and phase of nano material by electrical explosion of wire method.

\section{References}

Grassian V H 2008 When size really matters: Size dependent properties and surface chemistry of metal and metal oxide nanoparticles in gas and liquid phase environments. J. Phys. Chem. C 112: 18303-18313

Kotov Y A, Beketov I V, Demina T I, Murzakaev A M, Samatov O M, Schumacher G, Bohme R 1995 Characterization of $\mathrm{ZrO}_{2}$ nanopowders produced by electrical explosion of wires. J. Aerosol Sci. 26: S905-S906

Kotov Yu A 2003 Electrical explosion of wires as a method for preparation of nanopowders. J. Nanoparticle Res. 5: 539-550

Mao Z, Zou X, Wang X, Liu X, Ziang W 2009 Circuit simulation of the behaviour of exploding wires for nano powder production. Laser and Particle Beams 1: 1-7

Muraia K, Watanabe Y, Saito Y 2002 Preparation of copper nanoparticles with an organic coating by a pulsed wire discharge method. J. Ceramic Processing Res. 8: 114-118

Neuber Andreas A 2005 Explosively driven pulsed power, USA: Springer p.205

Suematsu H, Nishimura S, Murai K, Hayashi Y, Suzuki T, Nakayama T, Jiang W, Yamazaki A, Seki K, Niihara K 2007 Pulsed wire discharge apparatus for mass production of copper nanopowders. Rev. Scientific Instrum. 78: 056105-1-056105-3 